\title{
Augmented medial rectus recession in the management of esotropia
}

\author{
H E WILLSHAW, N MASHHOUDI, AND S POWELL \\ From the Department of Paediatric Ophthalmology, Children's Hospital, Birmingham
}

SUMMARY Forty-six children awaiting surgery for concomitant esotropia were placed into two matched groups. One group received bilateral medial rectus recessions, while the second group received augmented bilateral medial rectus recessions. By recessing the conjunctiva and subconjunctival tissue in addition to the medial rectus we consistently increased the correction obtained. With bilateral medial rectus recession to correct large angle esotropia application of the augmented technique is more likely to provide a full correction.

In the surgical management of concomitant esotropia there are a number of potential advantages in the use of symmetrical medial rectus recessions rather than recession and resection of both horizontal recti of one eye. These include preservation of all muscle tissue, a reduced incidence of postoperative granuloma formation,' and a reduced tendency to induce astigmatism in the early postoperative period. ${ }^{2}$ However, for the surgeon wishing to employ symmetrical recessions of the medial recti there is concern that medial rectus recessions alone may be inadequate fully to correct large angle esotropia. We therefore considered it worthwhile to explore the possibility of augmenting the effect of bilateral medial rectus recessions in large angle esotropia by simultaneously recessing the overlying conjunctiva and anterior Tenon's capsule.

\section{Patients and methods}

Two groups of children receiving surgery for large angle concomitant esotropia were compared. The groups were matched for sex, age at the time of surgery, type of convergent deviation, preoperative angle of deviation, refractive error, degree of amblyopia, and the potential for binocular single vision as assessed at the preoperative examination by tests appropriate for age.

One group of children then received bilateral medial rectus recessions with full reapposition of the conjunctiva, while the second group received (in

Correspondence to Mr H E Willshaw, Children's Hospital, Ladywood Middleway, Birmingham B16 8ET addition to their muscle recessions) recession of the conjunctiva and Tenon's capsule to a maximum of $5 \mathrm{~mm}$ from the limbus, or to a point immediately in front of the original muscle insertion if this was less than $5 \mathrm{~mm}$ (Fig. 1).

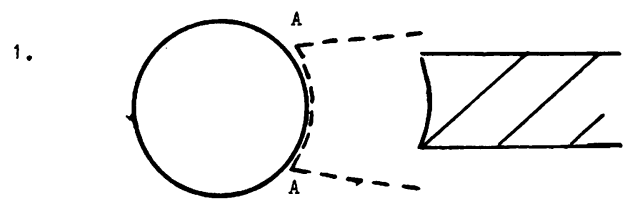

Limbal Peritomy with radial relieving incisions.

2.

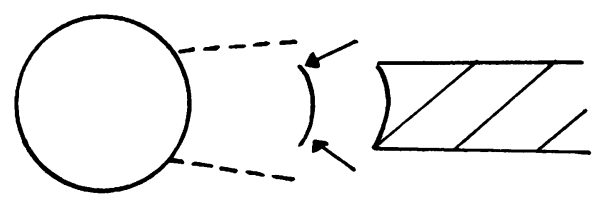

Muscle recession.

Arrows indicate original muscle insertion.

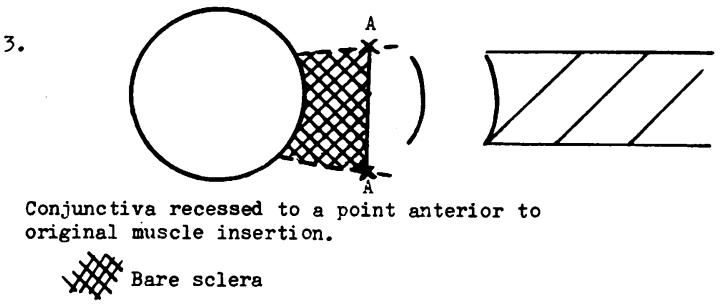

Fig. 1 Technique of conjunctival recession. 
Table 1 Comparison of patients receiving conventional bimedial recessions (group I) with those receiving augmented bimedial recessions (group 2)

\begin{tabular}{lll}
\hline & Group I & Group 2 \\
\hline Mcan age at surgery & $39 \cdot 5$ (months) & $39 \cdot 8$ (months) \\
Mcan preop. deviation & $41 \cdot 5$ (prism dioptres) & $48 \cdot 9$ \\
M:F & $13: 10$ & $13: 10$ \\
No amblyopia: amblyopia & $21: 2$ & $20: 3$ \\
Potential BSV & 4 & 4 \\
Emmetropia & 14 & 13 \\
Hypermetropia >2.00 DS & 4 & 4 \\
Astigmatism >1·00 DC & 3 & 3 \\
Unilateral:alternating & $16: 7$ & $8: 15$ \\
Congenital:non-congenital $11: 12$ & $10: 13$ \\
\hline
\end{tabular}

The surgery was carried out by one of us (HEW) or under his direct supervision, and was by our standard technique of muscle exposure, a limbal conjunctival incision, with two radial relieving incisions. The muscles were secured to the globe by a $6 / 0$ gauge coated polyglactin suture, and the limbal conjunctival incision was closed with four interrupted 8/0 virgin silk sutures when full reapposition was employed, and either two or four interrupted virgin silk sutures when the conjunctiva was recessed. The reduction in the angle of deviation was then assessed two weeks, six weeks, and six months after surgery, and the prism dioptres of correction per millimetre of muscle recession were compared in the two groups.

\section{Results}

Each group contained 23 children, and their details are shown in Table 1. Except for the number of

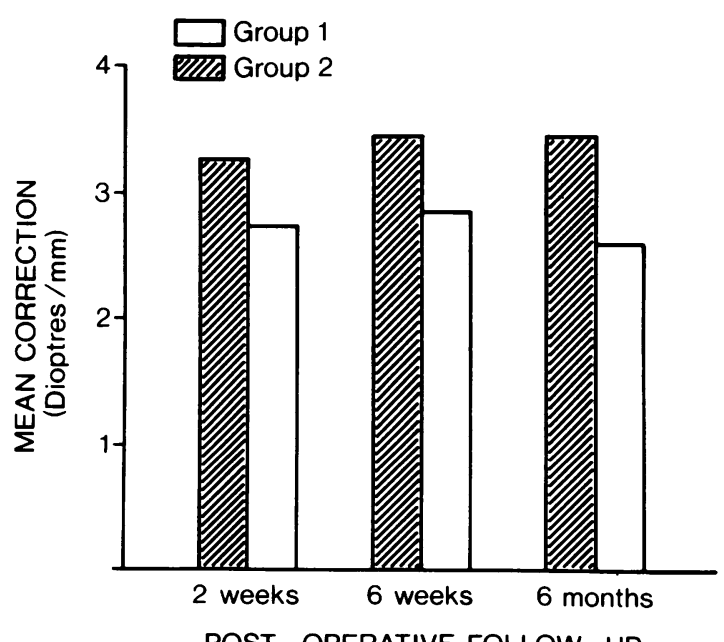

Fig. 2 Comparison of the mean correction achieved (prism dioptres per mm recession) at 2 weeks, 6 weeks, and 6 months for the two groups. children showing free alternation preoperatively, statistical analysis revealed no significant differences between the two groups.

The mean correction in prism dioptres per millimetre of muscle recession was calculated for the two groups at the three follow-up intervals (Fig. 2). Detailed examination of the two groups showed that the factors which had greatest influence on the amount of correction achieved were the age of the patient at the time of surgery and the size of the preoperative deviation. The two groups were therefore further analysed to determine the correction achieved two weeks, six weeks, and six months postoperatively for children of different ages (Fig. 3), and with different preoperative angles of deviation (Fig. 4) by the two surgical approaches. With either factor it was again found that the augmented recession produced a greater effect.

No difference was found in the response to surgery of either type between those children considered to have the potential for binocular single vision and those considered to have constant suppression. Similarly no difference in response to surgery was found between children with different refractive errors or differing durations of strabismus prior to their surgery-though all these factors are being examined in a much larger series.

\section{Discussion}

Such is the variability of individual response to extraocular muscle surgery that comparisons of the

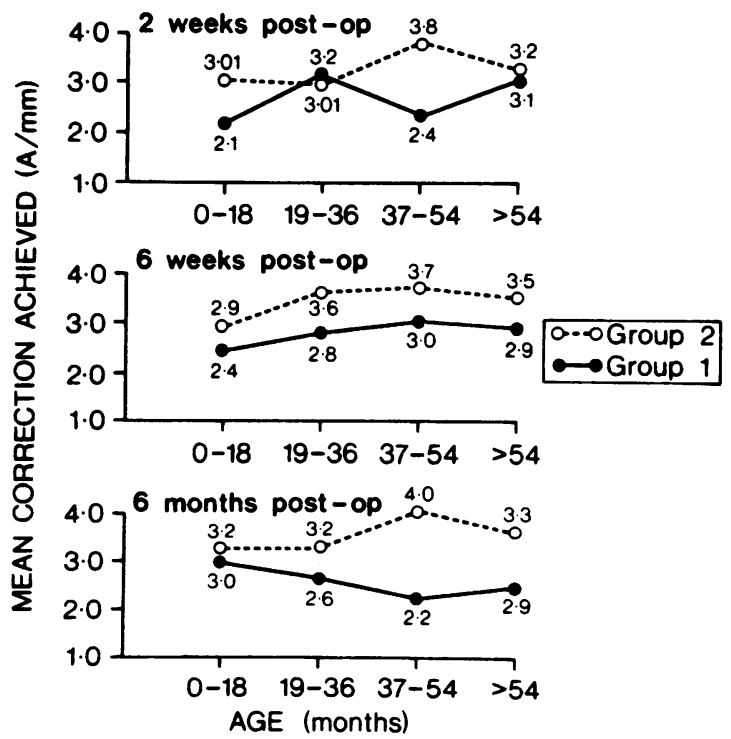

Fig. 3 Comparison of the mean correction achieved with each technique in children of different ages at the time of surgery. 


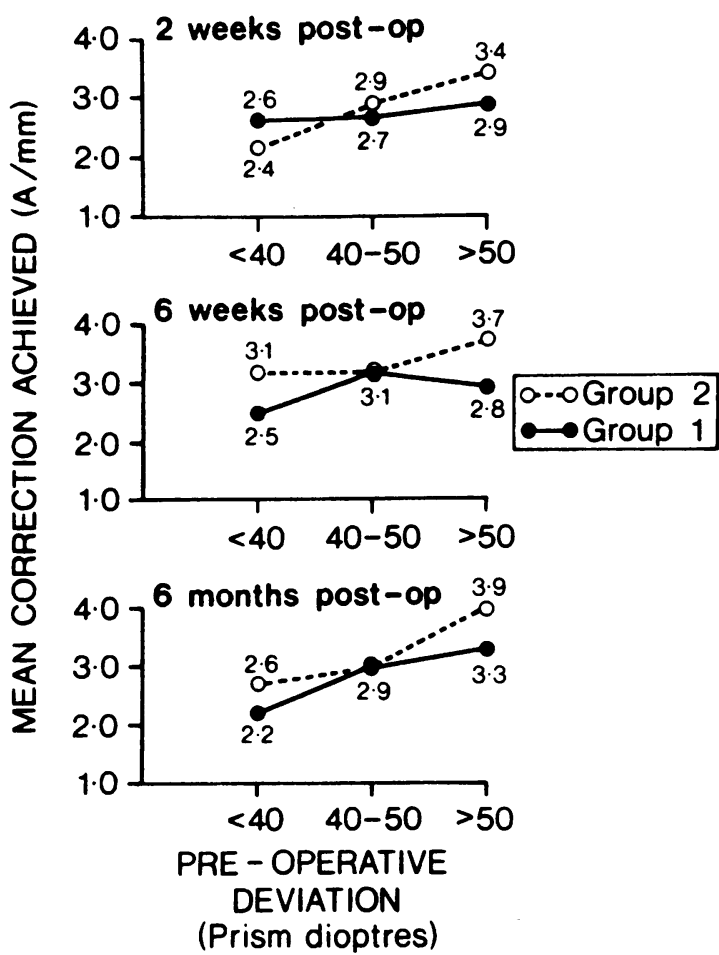

Fig. 4 Comparison of the mean correction achieved with each technique, in children with different preoperative angles of deviation.

response to different surgical procedures are difficult to analyse statistically. None the less, all the comparisons we have used demonstrate an augmentation of the effectivity of bilateral medial rectus recession when it is combined with a conjunctival recession.

The importance of changes in conjunctiva and Tenon's capsule in contributing to the mechanical components of strabismus in thyroid eye disease has long been recognised. ${ }^{3}$ Similarly, many authorities have emphasised the need for repeated force duction testing during the correction of cicatricial strabismus, recognising that multiple tissue components contribute to the overall effect. ${ }^{+}$However, relatively little has been written on the influence of nonmuscular elements in determining the size of an uncomplicated concomitant strabismus. Since we have been able to demonstrate an increased effect with this augmented surgery (confirming the report of Helveston et al. ${ }^{5}$ ) it must be assumed that in a longstanding deviation, even with a full range of ocular movements, secondary changes occur in conjunctiva and Tenon's capsule which tend to increase the underlying angle of squint. This being so, it is perhaps surprising that no increased augmentation is found in children with longer durations of squint prior to surgery. However, no children in this series were operated on less than six months after the onset of their strabismus. One would also expect that in the large angle congenital esotropia with habitual limitation of abduction the changes in conjunctiva and Tenon's capsule would be greater, and thus the influence of non-muscular recession also greater. This proved to be the case, with a mean increase in effect of 0.87 dioptre per $\mathrm{mm}$ of muscle recession (a $30.9 \%$ increase) achieved six weeks postoperatively in those squints measuring 50 dioptres or more preoperatively.

Recent reports ${ }^{67}$ have advocated the use of supramaximal recession of the medial recti for large angle deviations and have reported no postoperative convergence weakness. We routinely employ $6 \mathrm{~mm}$ recessions for large angle esotropias and, with the added effect from augmented recession, have only rarely been troubled by significant residual esotropia. For this reason we have not yet resorted to the larger recessions which are apparently possible.

The even greater augmentation achieved by Helveston et al. ${ }^{5}$ with this technique is difficult to explain but may relate to differences in technique, and in particular the extent of the peritomy used to approach the muscle and therefore the volume of conjunctiva released.

Certain differences in the behaviour of eyes receiving this bare sclera closure have been noted but not analysed in detail. Firstly, the eyes tend to be 'whiter' in the immediate postoperative period. Secondly, it has been our impression that postoperative discomfort may be a little more prolonged (by one or two days), as is commonly experienced when using a bare sclera closure after adjustable suture surgery. ${ }^{8}$ Finally, caution must be exercised in covering the site of the original medial rectus insertion with conjunctiva, since failure to do so may result in unacceptable cosmesis.

\section{CONCLUSION}

In large angle esotropia (greater than 40 prism dioptres) the surgeon employing bilateral medial rectus recession as his primary procedure may wish to enhance the effect of conventional surgery rather than employ supramaximal recessions (of 7 or $8 \mathrm{~mm}$ ). In this case combining the muscle recession with recession of the overlying conjunctiva and Tenon's capsule is an effective and simple measure.

\section{References}

1 Elkington AR. Granulomas following squint surgery. Trans Ophthalmol Soc UK 1971; 42: 543-52.

2 Aggarwal SP. Comparison of symmetrical and asymmetrical surgery in the management of esotropia : induced astigmatism. Midland Ophthalmological Society: Registrars' prize, 1985.

3 Burian HM, Von Noorden GK. In: Binocular vision and ocular motility. 2nd ed. St Louis: Mosby, 1980: 392. 
4 Dunlap EA. Surgery of muscle adhesions and effects of multiple operations. BrJ Ophthalmol 1974; 58: 307-12.

5 Helveston EM, Patterson JH, Forrest DL, Weber J. En-bloc recession of the medial recti for concomitant esotropia. In: Symposium on strabismus. Transactions of the New Orleans Academy of Ophthalmology. St Louis: Mosby, 1978: 230.

6 Szmyd SM, Nelson LB, Calhoun JH, Spratt C. Large bimedial rectus recessions in congenital esotropia. $\mathrm{Br} J$ Ophthalmol 1985; 69: 271-4.
7 Pricto-Diaz J. Large bilateral medial rectus recession in early esotropia with bilateral limitation of abduction. J Pediatr Ophthalmol Strabismus 1980; 17: 101-5.

8 Jasmpolsky A. Adjustable strabismus surgical procedure. In: Symposium on strabismus. Transätions of the New Orleans Academy of Ophthalmology. St Louis: Moshy, 1978: 32.

Accepted for publication 21 February 1986. 